\title{
VARIATION AND EVOLUTION IN SOUTH AMERICAN CLARKIA
}

\author{
D. M. MOORE and HARLAN LEWIS \\ Botany Department, University of Leicester and \\ Botany Department, University of California, Los Angeles
}

Received 5.v.65

\section{INTRODUCTION}

The genus Clarkia (Onagracex), currently considered to contain 36 species, is restricted to the western parts of North and South America (fig. I). The 35 North American species are distributed from Baja California to British Columbia $\left(30^{\circ} \mathrm{N}\right.$. to $48^{\circ} \mathrm{N}$.), most of them occurring in California. The South American populations, which have a smaller though still considerable latitudinal spread $\left(29^{\circ} 30^{\prime} \mathrm{S}\right.$. to $42^{\circ} 30^{\prime} \mathrm{S}$.), comprise a single variable species, Clarkia tenella (Cav.) H. and M. Lewis (Lewis and Lewis, 1955), within which four subspecies have been recognised (Moore and Lewis, $1965^{b}$ ).

Clarkia tenella is tetraploid, having $2 n=34$ (Hiorth, I94I; Raven and Lewis, 1959) and $2 n=32$ (Moore and Lewis, $1965 b)$. It is placed in section Godetia, together with seven North American species, and shows its closest affinities with the only tetraploid among these, $C$. davyi (Jeps.) H. and M. Lewis. A study of artificial hybrids between $C$. tenella and $C$. davyi, together with palæo-ecological evidence, led Raven and Lewis (1959) to hypothesise that the two species were derived from a common tetraploid ancestor which had traversed the tropics by long-distance dispersal during or since the Late-Tertiary and given rise to the populations now comprising C. tenella.

Detailed study of the variation within Clarkia tenella was made possible by a field trip to Chile and Argentina during 1960-61 and by subsequent experimental work at Leicester and Los Angeles. The data thus obtained are given here and are used to examine the interrelationships of the South American populations and the course of evolution within $C$. tenella.

\section{DISTRIBUTION AND HABITAT}

Clarkia tenella occurs mainly on the west side of the Andes (fig. 2), ranging from the region around La Serena, Prov. Coquimbo $\left(29^{\circ} 30^{\prime}\right.$ S.) through central Chile to Prov. Osorno $\left(40^{\circ} 30^{\prime} \mathrm{S}\right.$.), with a single disjunct occurrence further south on the island of Chiloe $\left(42^{\circ} \mathrm{S}\right.$.). The few stations in Argentina lie between Las Ovejas, Prov. Neuquen $\left(37^{\circ}\right.$ S.) and Río Corcovado, Prov. Chubut $\left(42^{\circ} 30^{\prime}\right.$ S. $)$, an area which is climatically comparable to north central Chile because it lies in the rain shadow of the Andes. 
Clarkia tenella occurs from sea-level to about $1400 \mathrm{~m}$. and on a variety of substrates, varying from almost pure sand or gravel to shaley

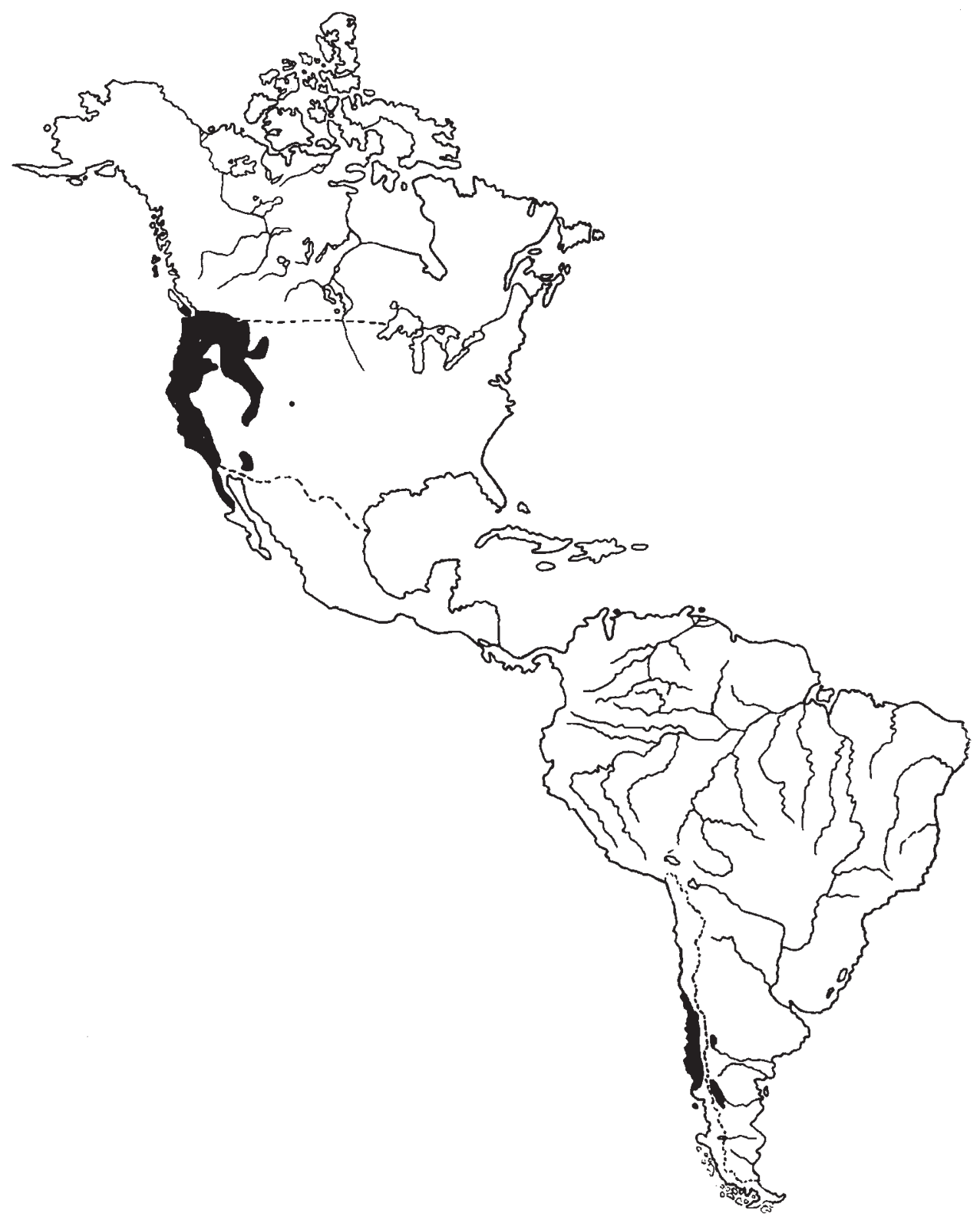

Fig. I.-Distribution of the genus Clarkia.

or even rather clay soils, whose common features seem to be that they are reasonably well-drained and bare or but sparsely vegetated. Characteristically it grows in open maquis or scrubby, sclerophyllous, 


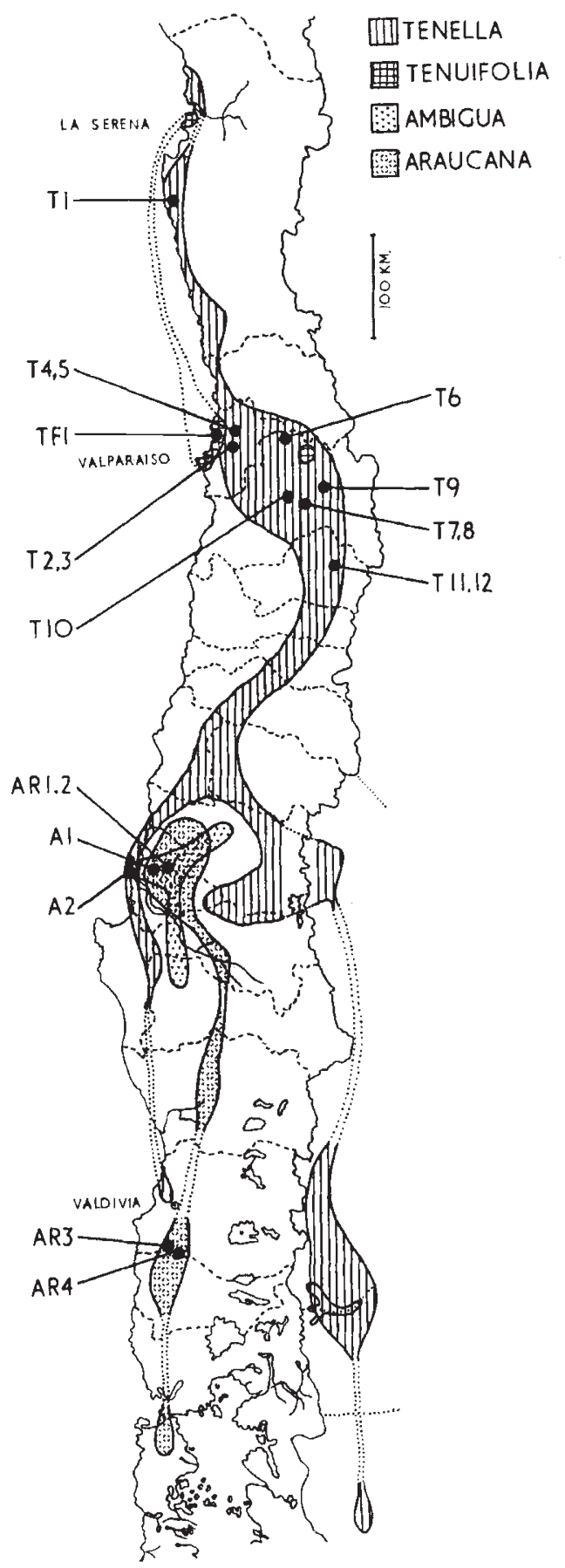

Fig. 2.-Distribution of the subspecies of Clarkia tenella in Chile and western Argentina. Populations used in the hybridisation programme are indicated by their crossing code (see table 2): $\mathrm{T}=$ ssp. tenella, $\mathrm{TF}=$ ssp. tenuifolia, $\mathrm{A}=$ ssp. ambigua, $\mathrm{AR}=\mathrm{ssp}$. araucana. 
savannah-woodland communities in areas having light to moderate winter rainfall $\left(4^{\cdot 2-1} \cdot 2 \cdot 6 \mathrm{~cm}\right.$. per month) and rather dry summers (0-1.8 cm. per month). This type of vegetation is well-developed in the Chilean coast ranges and in the Andean foothills, regions where C. tenella is most frequently encountered. These communities have an open scrub composed of such genera as Acacia, Baccharis, Berberis, Cassia, Lithraea, Peumus and Trevoa, with a ground layer largely comprising spring-flowering herbs, many of them annual, and including several aliens from other warm-temperate regions of the Old and New Worlds. In coastal areas, from Prov. Valparaiso northwards, C. tenella often occurs on stabilised sand dunes. It is frequent in open habitats resulting from man's activities-road verges and ditch margins, sandy washes, road and rail cuttings. This is particularly true towards the south, where the Río Bío-Bío marks the transition to a higher rainfall area (150-250 $\mathrm{cm}$. per annum) characterised by a much more mesic vegetation type, the Valdivian Forest. For example, two populations ( $\mathrm{AR}_{3}, \mathrm{AR}_{4}$ ) occurring near the town of La Unión, Prov. Valdivia, inhabit open, well-drained habitats on the eroding bluffs flanking the flood plain of the Río Bueno and its tributary the Río Llollehue. Here, very many plants have spread to bare soil on the banks of a road-cutting and at the margin of a wheatfield.

The habitats favoured by Clarkia tenella closely parallel those of the N. American Clarkias. In general, these are associated with welldrained soils of open sites in the oak woodland-savannah and chaparral communities, less frequently with more xeric coastal and desert margin conditions. The northward expansion of such species as $C$. amcena, $C$. purpurea and $C$. rhomboidea, which extend into the higher rainfall areas of the north-western U.S.A. and southern British Columbia, is due to the utilisation of open, well-drained sites.

\section{MORPHOLOGICAL AND CYTOLOGICAL VARIATION}

\section{(i) Morphology and breeding system}

Clarkia tenella varies conspicuously in characters such as habit, leaf shape, petal shape and colour, pubescence, inflorescence structure, hypanthium length, and in characters associated with its pollinating mechanism. On the basis of field and herbarium studies, and cultivation experiments, four taxonomic entities have been recognised, differing in breeding system and in certain morphological characters. Since they intergrade morphologically to some extent, they are most appropriately described as subspecies (Moore and Lewis, $1965 b$ ). The characters of the four subspecies are summarised in table I and their distributions are shown in fig. 2. The most southerly of them, ssp. araucana Moore and Lewis, has large flowers and is completely outcrossing, having the receptive stigma raised well above the anthers. It is of robust, well-branched habit and seems to be almost entirely restricted to open, rather "weedy" habitats. Towards its northern 
limit, near Concepción, it grows sympatrically with ssp. ambigua (Phil.) Moore and Lewis, which is very sinilar, though with somewhat smaller petals and a shorter hypanthium. However, ssp. ambigua is self-pollinating and readily distinguished from ssp. araucana because the mature stigma scarcely projects from the hypanthium and never reaches the level of the anthers. The two subspecies are largely isolated by their different flowering periods when sympatric, since ssp. ambigua blooms in November and early December while ssp. araucana does not flower before the end of December. Subspecies tenuifolia (Cav.) Moore and Lewis, has flowers of comparable size to ssp. ambigua but it occurs much further north, typically in coastal localities. It is

TABLE :

Principal characters distinguishing the subspecies of Clarkia tenella

\begin{tabular}{|c|c|c|c|c|}
\hline Subspecies & Tenella & Tenuifolia & Ambigua & Araucana \\
\hline Petal length (mm.) & 8-15 & $(9-) 13-22(-25)$ & $(12-) 15^{-18}$ & $18-30$ \\
\hline Hypanthium length (mm.) & $1-3$ & $2-4 \cdot 5(-5)$ & $2 \cdot 5 \cdot 5$ & $6-12$ \\
\hline Pollinating mechanism & $\begin{array}{l}\text { selfing, anthers } \\
\text { in contact } \\
\text { with stigma }\end{array}$ & $\begin{array}{c}\text { largely outcrossing, } \\
\text { stigma usually } \\
\text { slightly exceeding } \\
\text { anthers }\end{array}$ & $\begin{array}{c}\text { selfing, stigma } \\
v . \text { short, not } \\
\text { reaching anthers }\end{array}$ & $\begin{array}{l}\text { outcrossing, stigma } \\
\text { much exceeding } \\
\text { anthers }(3 \mathrm{~mm} .<)\end{array}$ \\
\hline Flowering period . & $X-I$ & IX-XII & XI-XII (early) & XII (late)-II \\
\hline Distribution (fig. 2) & $\begin{array}{l}\text { N. central to } \\
\text { S. central Chile } \\
\text { Argentina }\end{array}$ & $\begin{array}{l}\text { N. central Ghile } \\
\text { (coastal) }\end{array}$ & S. central Chile & $\begin{array}{l}\text { S. central to } \\
\text { S. Chile }\end{array}$ \\
\hline Chromosome number $(n)$ & 17 & 17 & 17 & 16,17 \\
\hline
\end{tabular}

at least partially outcrossing, with the mature stigma usually held above the level of the dehisced anthers. However, many populations have some plants, which constitute the smaller-flowered facies, indistinguishable from ssp. tenella. Like it they are autogamous, with the dehiscing anthers in contact with the mature stigma, so that pollination is effected at or shortly after anthesis. The small-flowered ssp. tenella is the commonest and most widespread subspecies in Central Chile and the only one in Argentina. There are constant differences in various characters between many populations of ssp. tenella and plants may be glabrous to pubescent, have oblanceolate and truncate to linear and long-petiolate leaves, blue to purple or even "burgundy" red flowers or an elongate to compact inflorescence rachis. This variation cannot be resolved further at present and the pattern undoubtedly results from the high degree of autogamy producing a series of slightly different biotypes. 


\section{(ii) Cytology}

Chromosome numbers have been determined from material covering virtually the whole range of Clarkia in South America (table 2).

\section{TABLE 2}

Chromosome numbers in Clarkia tenella. Populations used in experimental programme are indicated by their crossing code. Field collections made by Moore. Vouchers deposited at Los Angeles and Leicester

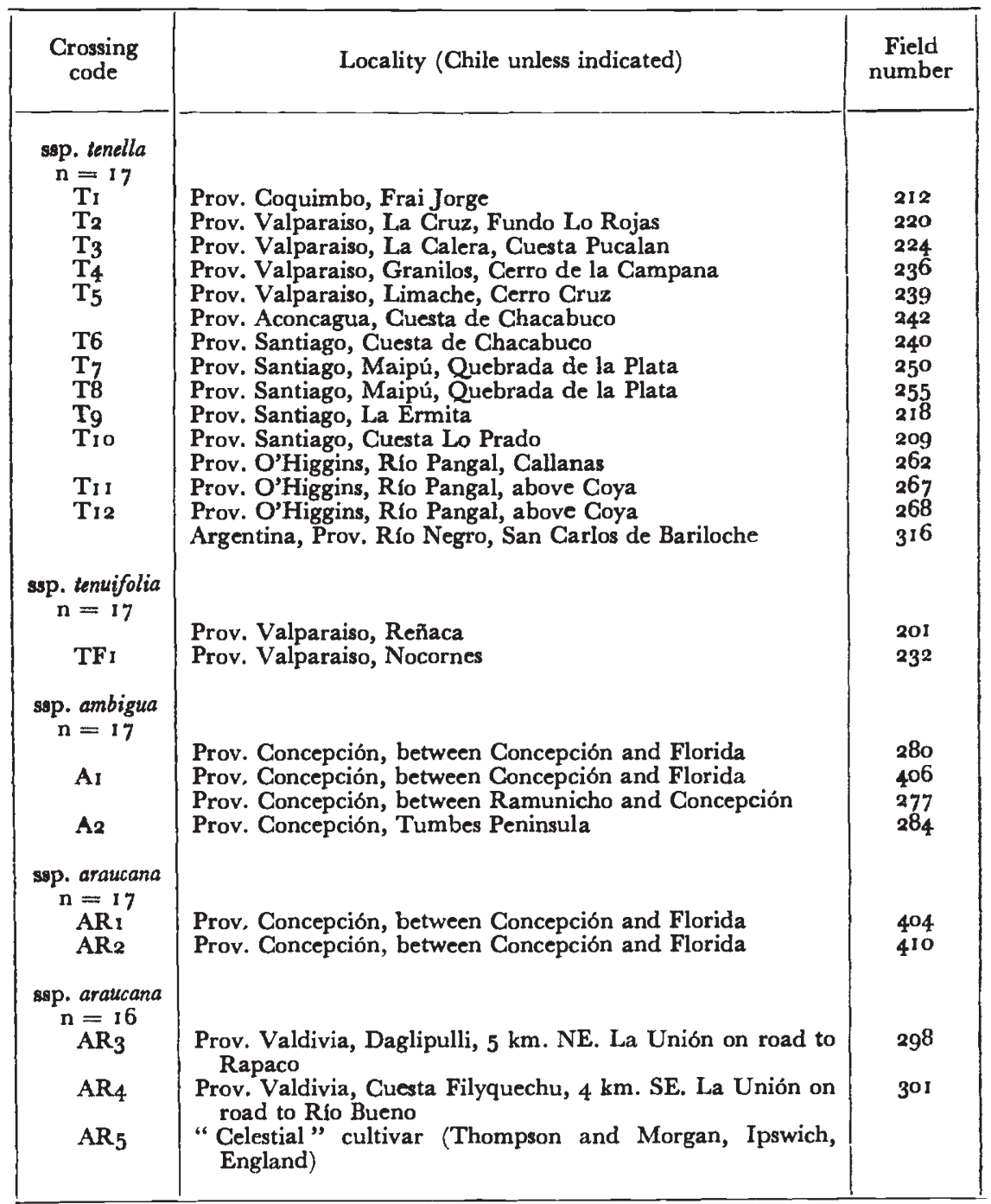

All populations sampled within sspp. tenella, tenuifolia and ambigua, and the northern populations of ssp. araucana, have 17 bivalents. This 
number was previously recorded by Hiorth (I94I) and by Raven and Lewis (1959). One sample of ssp. ambigua (Moore 280) and one of ssp. araucana (Moore 404) had some plants in which up to 20 per cent. of the pollen mother cells showed a chain of four chromosomes and fifteen bivalents; a similar situation was earlier reported in a plant of ssp. tenella from Limache, Prov. Valparaiso (Raven and Lewis, I959). The two southernmost populations of ssp. araucana examined showed a regular formation of sixteen bivalents. This number was hitherto known within the genus Clarkia (R. Snow, unpublished) only for the cultivated form of C. tenella known as "Celestial ", which is morphologically indistinguishable from ssp. araucana.

\section{CYTOLOGY AND FERTILITY OF INTERPOPULATIONAL $F_{1}$ HYBRIDS}

Seed from nineteen populations was used to raise garden progenies for study in pot culture and to produce interpopulational and intersubspecific hybrids. The populations selected (table 2, fig. 2) were representative of the geographical, morphological and cytological variation within the species. In addition, the cultivar "Celestial" was included in the crossing programme.

Chromosome pairing was examined at first meiotic metaphase in pollen mother cells following anther squashes in acetocarmine. In most hybrids catenations of four or more chromosomes were observed (table 3). The constancy of the number of chromosomes involved in multiple associations, which is shown by crosses of the same type, indicates that the catenations are due to interchange heterozygosity and not to genotypically-induced breakage. Breakage may occur, however, as is suggested by the irregular presence of anaphase bridges with fragments of varying size inconstantly associated with them. This can be seen particularly in some of the crosses between cytologically very dissimilar populations, in which up to five bridges may be present. It is practicable to present the cytological data only in the abbreviated form used, but two general points should be mentioned before considering them in further detail:

r. Where only small catenations are possible, they are reasonably constant in size. 2. Where large catenations are possible, great variation is observed in the size of chromosomal associations. In table 3 it will be noted that the suggested minimum number of interchanges is sometimes higher than required by the number of chromosomes involved in catenations in the configuration showing maximum multivalent formation. This results from the variation in catenation size between pollen mother cells already mentioned, which can only be reconciled in such cases by hypothesising larger catenations than were actually observed in any one cell.

Pollen fertility data (table 3) were obtained by scoring for stainability in cotton blue and lactophenol. 
TABLE 3

Chromosome pairing and pollen fertility of interpopulational hybrids in C. tenella. The number of interchanges differentiating the populations is based on the maximum configuration given but takes into account catenations in other cells (see text)

\begin{tabular}{|c|c|c|c|c|c|c|c|}
\hline \multicolumn{2}{|c|}{ Cross } & $\begin{array}{l}\text { No. } \\
\text { pls. }\end{array}$ & $\begin{array}{l}\text { No. } \\
\text { cells }\end{array}$ & $\begin{array}{l}\text { Maximum multivalent } \\
\text { configuration }\end{array}$ & $\begin{array}{c}\text { No. } \\
\text { chromo- } \\
\text { somes } \\
\text { in all } \\
\text { catena- } \\
\text { tions }\end{array}$ & $\begin{array}{c}\text { Min. } \\
\text { No. } \\
\text { inter- } \\
\text { changes } \\
\text { involved }\end{array}$ & $\begin{array}{c}\text { Per } \\
\text { cent. } \\
\text { pollen } \\
\text { fertility }\end{array}$ \\
\hline \multicolumn{8}{|c|}{ araucana-32-araucana- 32} \\
\hline $\mathrm{AR}_{3}$ & $\mathrm{AR}_{4}$ & 2 & 17 & $\mathrm{IV} \odot+14 \mathrm{II}$ & 4 & 1 & $9^{\mathrm{I}}$ \\
\hline & $\mathrm{AR}_{5}^{2}$ & 2 & 23 & $I V \odot+14 I I$ & 4 & 1 & 95 \\
\hline \multicolumn{8}{|c|}{ araucana-32-araucana-34 } \\
\hline $\mathrm{AR}_{3}$ & $\mathrm{AR}_{2}$ & 1 & 10 & $2 \mathrm{VI}^{c h}+10 \mathrm{II}+\mathrm{I}$ & 12 & 5 & 50 \\
\hline $\mathrm{AR}_{4}$ & $\mathrm{AR}_{2}$ & 1 & 8 & $V^{c h}+I V^{c h}+I I I^{c h}+10 I I+I$ & 12 & $4(5)$ & 50 \\
\hline $\mathrm{AR}_{5}$ & $\mathrm{AR}_{2}$ & 2 & 24 & $\mathrm{VI}^{c h}+\mathrm{I} V^{c h}+10 \mathrm{II}+\mathrm{III}$ & 10 & & 45 \\
\hline $\mathrm{AR}_{4}$ & $A R_{I}$ & 3 & 32 & $V^{c h}+I V^{c h}+I I I I^{c h}+10 I I+I$ & 12 & $4(5)$ & $5^{8}$ \\
\hline $\mathrm{AR}_{5}$ & ARI & 1 & 5 & VIII ${ }^{\iota h}+I V \odot+9 I I+I I I$ & 12 & & 50 \\
\hline \\
\hline $\mathrm{AR}_{2}$ & & $\cdots$ & $\cdots$ & & $\cdots$ & $\ldots$ & 20 \\
\hline \multicolumn{8}{|c|}{ araucana-32- ambigua } \\
\hline & $\mathrm{Al}_{1}$ & 1 & 21 & $\mathrm{XII} \mathrm{II}^{\iota h}+\mathrm{IV}^{c h}+8 \mathrm{II}+\mathrm{I}$ & 16 & $6(7)$ & 14 \\
\hline $\mathrm{AR}_{5}$ & & 2 & 21 & $2 I V^{o h}+2 I I I^{e h}+9 I I+I$ & 14 & $4(6)$ & 23 \\
\hline \multicolumn{2}{|c|}{ araucana-32- tenuifolia } & 3 & 22 & $\mathrm{VI}^{e \lambda}+\mathrm{V}^{e \lambda}+2 \mathrm{IV}^{e \lambda}+2 \mathrm{III} \mathrm{I}^{e \lambda}+4 \mathrm{II}$ & 24 & 11 & 9 \\
\hline \multicolumn{8}{|c|}{ araucana-32- tenella } \\
\hline $\mathrm{AR}_{5}$ & $T_{11}$ & I & 8 & $\mathrm{X}^{c h}+\mathrm{VIII}^{e h}+\mathrm{III}^{c h}+5 \mathrm{II}+2 \mathrm{I}$ & 18 & 8 & $4^{\mathrm{I}}$ \\
\hline & $\mathrm{T}_{12}$ & 1 & 19 & $X \Pi^{c h}+I V^{c h}+8 \Pi+1$ & 16 & 7 & $5^{2}$ \\
\hline \multicolumn{2}{|c|}{ ambigua - ambigua } & 1 & 12 & $\mathrm{VI}^{e n}+\mathrm{V}^{e n}+\mathrm{IV}^{e n}+9 \mathrm{II}+\mathrm{I}$ & 16 & $7(8)$ & 3 \\
\hline \multicolumn{8}{|c|}{ ambigua - tenella } \\
\hline $\mathrm{A}_{1}$ & $T_{11}$ & i & 7 & $\mathrm{X}^{c h}+\mathrm{V}^{c h}+\mathrm{I} \mathrm{V}^{c h}+7 \mathrm{II}+\mathrm{I}$ & 20 & $7(9)$ & 22 \\
\hline A2 & T6 & 1 & 11 & $\mathrm{X}^{c h}+\mathrm{VII}^{c h}+\mathrm{III}^{c h}+7 \mathrm{II}$ & 20 & & 22 \\
\hline \multicolumn{8}{|l|}{ tenuifolia - } \\
\hline $\begin{array}{l}\mathrm{TF}_{1} \\
\mathrm{TF}_{1}\end{array}$ & $\begin{array}{l}\mathrm{T}_{2} \\
\mathrm{~T}_{10}\end{array}$ & $\begin{array}{l}2 \\
2\end{array}$ & $\begin{array}{l}14 \\
12\end{array}$ & $V I I I^{o n}+V^{e b}+V^{c h}+7 I I+I$ & 20 & $8(9)$ & $\begin{array}{l}20 \\
19\end{array}$ \\
\hline $\mathrm{TF}_{1}$ & $T_{11}$ & 1 & 13 & VIIII $I^{c h}+V^{I^{c h}}+I^{c} V^{c h}+I I I^{c h}$ & 22 & $8(10)$ & 12 \\
\hline $\mathrm{TF}_{1}$ & $T_{3}$ & 1 & 2 & $3 V I^{c h}+I V^{c h}+6 I I$ & 22 & $8(10)$ & 13 \\
\hline TFI & $T_{4}$ & 1 & 8 & $V^{c h}+4 I V^{o n}+6 I I+I$ & 22 & $8(10)$ & 17 \\
\hline TFi & $T_{5}^{4}$ & 1 & 7 & $\mathrm{X}^{c h}+\mathrm{VII} I^{c h}+\mathrm{III} I^{c h}+7 \mathrm{II}$ & 20 & 9 & 9 \\
\hline $\mathrm{TF}_{1}$ & $T_{I}$ & 3 & 21 & $\mathrm{VIII}^{c h}+2 \mathrm{~V}^{o h}+\mathrm{IV}^{c h}+6 \mathrm{II}$ & 22 & $9(10)$ & 8 \\
\hline $\mathrm{TF}_{1}$ & T6 & 2 & 14 & $\mathrm{XII}^{e h}+\mathrm{VIIII}^{e h}+\mathrm{IV}^{e h}+{ }_{5} \mathrm{II}$ & 24 & $9(10)$ & 17 \\
\hline $\mathrm{TF}_{1}$ & $T_{9}$ & 1 & 8 & $V^{\prime I I I} I^{c h}+2 V^{c h}+2 I I I^{o h}+5 I I$ & 24 & $9(11)$ & 14 \\
\hline TF 1 & T8 & 4 & 35 & $V^{e n}+I V^{e h}+5 I I I I^{e h}+5 I I$ & 24 & $10(11)$ & 14 \\
\hline $\mathrm{TF}_{\mathbf{I}}$ & $\mathrm{T}_{7}$ & $i$ & 14 & $2 \mathrm{VIII}{ }^{\hat{c} h}+2 \mathrm{~V}^{\hat{c} \hat{h}}+5 \mathrm{II}$ & 24 & 11 & 2 \\
\hline \multicolumn{8}{|c|}{ tenella } \\
\hline$T_{4}$ & Tro & 3 & $4^{2}$ & $17 \mathrm{II}$ & o & o & 90 \\
\hline T8 & T8 & 1 & 10 & $\mathbf{V I}^{\mathrm{eh}}+14 \mathrm{II}$ & 6 & 2 & 85 \\
\hline $\mathrm{T}_{7}$ & $\mathbf{T}_{1}$ & $i$ & 26 & $\mathrm{IV} \odot+\mathrm{IV} \mathrm{V}^{e n}+13 \mathrm{II}$ & 8 & 2 & 92 \\
\hline$T_{7}$ & $\mathrm{~T}_{9}$ & 1 & 11 & $I V \odot+I V^{c h}+13 I I$ & 8 & 2 & \\
\hline Tio & TI1 & 1 & 8 & $V^{c h}+I_{4} I I+I$ & 6 & 2 & 80 \\
\hline$T_{12}$ & TII & 1 & 14 & $I V^{c h}+I I I^{c h}+13 I I+I$ & 8 & 2 & \\
\hline$T_{5}$ & Tro & 1 & 10 & $I V^{c h}+I I I^{c h}+13 I I+I$ & 8 & $2(3)$ & 58 \\
\hline$T_{4}$ & $\mathrm{~T}_{5}$ & 2 & 17 & $I V \odot+I V^{c h}+I I I I^{o h}+I I I I+I$ & 12 & $3(4)$ & 40 \\
\hline $\mathrm{T}_{5}^{\mathrm{T}}$ & $T_{11}$ & 1 & 8 & VIII $\odot+I V \odot+11 I I$ & 12 & & 84 \\
\hline$T_{5}$ & T6 & 2 & 12 & $2 I V \odot+I V^{c h}+I I I^{c h}+9 I I+I$ & 16 & $4(5)$ & $5^{8}$ \\
\hline T6 & $T_{11}$ & 1 & 8 & VIIIO $+2 I V \odot+9 I I$ & 16 & & 70 \\
\hline $\mathrm{T}_{12}$ & T6 & 1 & 5 & $V I I^{o h}+V^{c h}+2 I V^{e n}+7 I I$ & 20 & $7(9)$ & $\cdots$ \\
\hline $\mathrm{T}_{9}$ & Tio & 2 & 30 & $\mathrm{X}^{\mathrm{ch}}+\mathrm{VIII}^{\mathrm{oh}}+\mathrm{V}^{\mathrm{ch}}+6 \mathrm{II}$ & 22 & 9 (10) & at \\
\hline
\end{tabular}


(i) Crosses between subspecies

It can be seen from table 3 and fig. 3 that in all crosses except that between ssp. araucana cultivar "Celestial" and ssp. ambigua $\left(\mathrm{AR}_{5} \times \mathrm{Ar}_{\mathrm{r}}\right)$, populations belonging to different subspecies differ by six or more interchanges. Subspecies araucana and ambigua, which are close morphologically, are the closest cytologically, differing by 4-7 interchanges. In all cases the intersubspecific hybrids have greatly

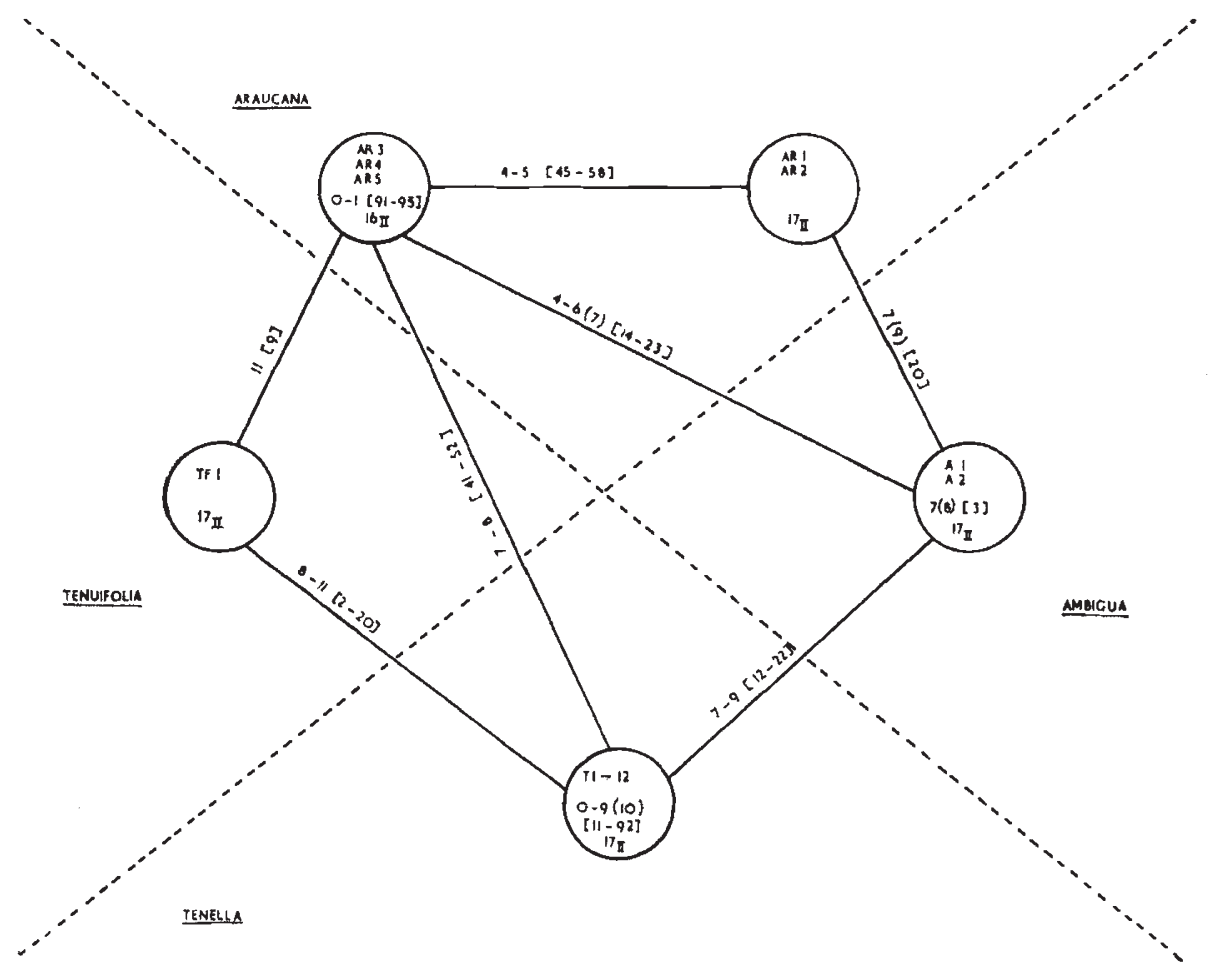

FIG. 3.-Diagram summarising the data on cytology and pollen fertility of $F_{I}$ hybrids between and within the subspecies of $C$. tenella. The maximum number of interchanges differentiating populations and, in square brackets, the maximum pollen fertility (per cent.) of the hybrids is given. The 32 and 34 chromosome races of ssp. araucana are distinguished. Population codes as in table 2.

reduced pollen fertility $(2-23(-52)$ per cent.). This does not entirely result from chromosomal differentiation, since by far the most fertile hybrids are between ssp. araucana- 32 and ssp. tenella which show marked chromosome differences, while hybrids between the cytologically most closely-related subspecies, araucana- 32 and ambigua, have a relatively low pollen fertility (I4-23 per cent.). Anaphase bridges, sometimes associated with fragments, were observed in several intersubspecific hybrids, though not in any between sspp. araucana and tenella. Because of their inconstancy, such bridges and fragments probably indicate that differentiation of subspecies has in some instances resulted in genotypes that produce chromosome breakage when combined in hybrids. 
However, it cannot be overlooked that the extensive chromosomal repatterning involved may have included inversions as well as the more prevalent reciprocal translocations.

The data show that considerable genetic and cytological differentiation exists between the morphologically separable subspecies. The greatest divergence appears to be between ssp. tenuifolia on one hand and both ssp. tenella and ssp. araucana on the other. This is particularly interesting since ssp. tenuifolia appears, on morphological grounds, to be intermediate between the other two. The two morphologically indistinguishable chromosome races of ssp. araucana differ appreciably in the extent of their chromosomal repatterning with respect to ssp. ambigua. The latter shows most differentiation from the sympatric araucana-34.

(ii) Crosses within ssp. araucana (table 3, fig. 4)

The two natural populations of ssp. araucana-32 differ from each other, and one of them differs from the 32-chromosome cultivar "Celestial " (AR 5$)$, by only a single interchange, while all the hybrids. are of high pollen fertility (91-95 per cent.). This situation is commonly encountered within a single parental population so that the unity of this chromosome race is confirmed. Although similar data are not

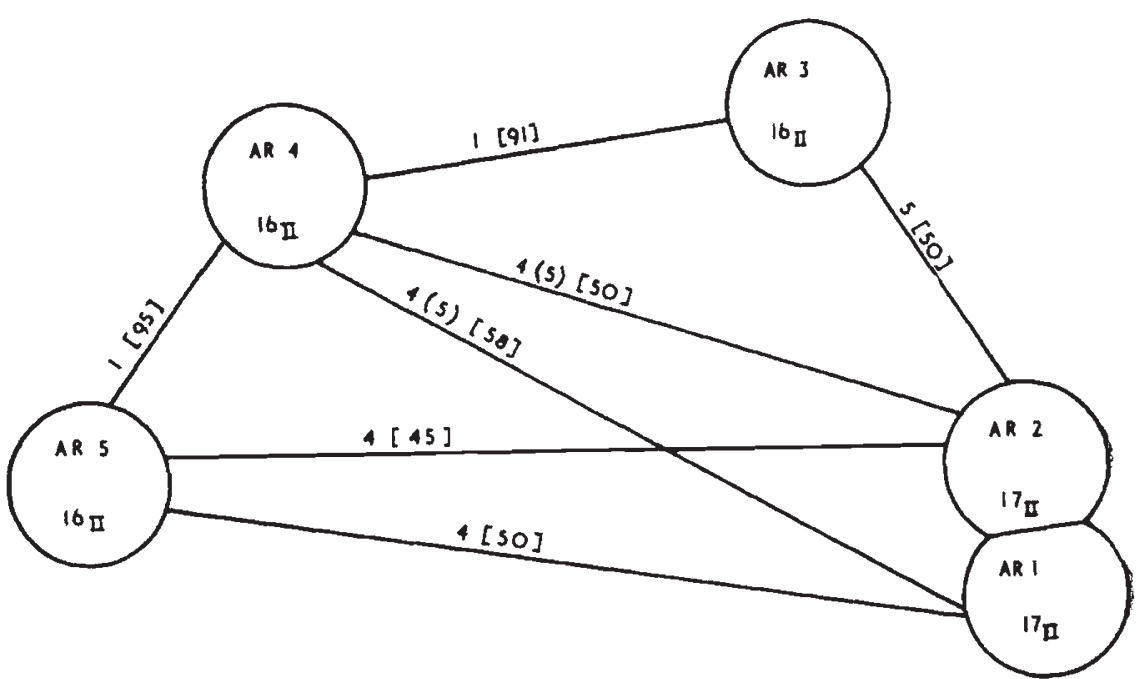

Frg. 4.-Diagram summarising the data on cytology and pollen fertility of $F_{I}$ hybrids between populations of ssp. araucana. For each cross is shown the maximum number of interchanges differentiating the parents and, in square brackets, the per cent. pollen fertility of the hybrid. Population codes as in table 2.

available on hybrids between the two 34-chromosome populations, they undoubtedly differ to no greater extent in view of the identical cytological situations in their hybrids with $\mathrm{AR}_{5}$.

In view of this cytological unity of each chromosome race it is not surprising that there is considerable uniformity in the various interpopulational hybrids between them. These hybrids, which are of 
reduced fertility ( $45^{-5} 5^{8}$ per cent.), indicate that the two races differ by at least four or five interchanges, as well as in chromosome number. In addition, bridges and sometimes fragments have been observed in one interracial hybrid $\left(\mathrm{AR}_{5} \times \mathrm{AR}_{2}\right)$. This differentiation has not been accompanied by any detectable morphological divergence but the more southerly occurrence of populations with 16 bivalents may indicate a difference in ecological tolerance. The extra chromosome of ssp. araucana-34 is included in a catenation of 3 , less commonly of 5 or 7 , chromosomes in about 50 per cent. of pollen mother cells in interracial hybrids. This may represent homœologous pairing within the 17 -genome or it may indicate that a chromosome in araucana- 32 has some homology with two araucana-34 chromosomes, including the extra one. If the latter is true, the frequent occurrence of the extra chromosome as a univalent in the hybrids suggests that the homologous region may be short.

\section{(iii) Crosses within ssp. ambigua (table 3)}

The two populations of ssp. ambigua used in the crossing programme are representative of the morphological variation found within the taxon. Population Ar, which is sympatric with the 34-chromosome race of ssp. araucana, is close to that subspecies in flower size and arrangement, although differing in hypanthium length and pollinating system. Population A2, on the other hand, bears the smallest flowers found in ssp. ambigua and has a somewhat congested inflorescence. Considerable differences exist between the chromosomes of the two populations, involving at least 7 or 8 interchanges, and hybrids between them are almost completely sterile ( 3 per cent. pollen fertility). The extent of chromosomal repatterning within ssp. ambigua almost equals that shown to exist between this subspecies and both ssp. tenella and ssp. araucana-34 while pollen fertility is appreciably higher in the intersubspecific hybrids.

\section{(iv) Crosses within ssp. tenella (table 3, fig. 5a)}

Interpopulational hybrids reveal a considerable range in the extent to which chromosomal repatterning has occurred within this subspecies. In $5^{\circ}$ per cent. of the crosses the populations differ by no more than two interchanges. This amount of differentiation can be encountered within a population (see $\mathrm{T} 8 \times \mathrm{T} 8$ ) and exists between the populations $\operatorname{Tr} 1$ and $\operatorname{Tr} 2$ which were only separated by about $6 \mathrm{~m}$. of bare rock. In contrast to this, populations $\mathrm{T}_{9}$ and $\mathrm{T}_{\mathrm{I}}$ differ by at least 9 interchanges and hybrids between them have only I I per cent. fertile pollen, divergence comparable to that existing between the subspecies. In addition, several bridges and fragments were observed in the hybrid. The remaining crosses between populations of ssp. tenella show differences of intermediate extent but in only one of them $\left(\mathrm{T} 6 \times \mathrm{TII}_{\mathrm{I}}\right)$ were bridges and fragments observed. 

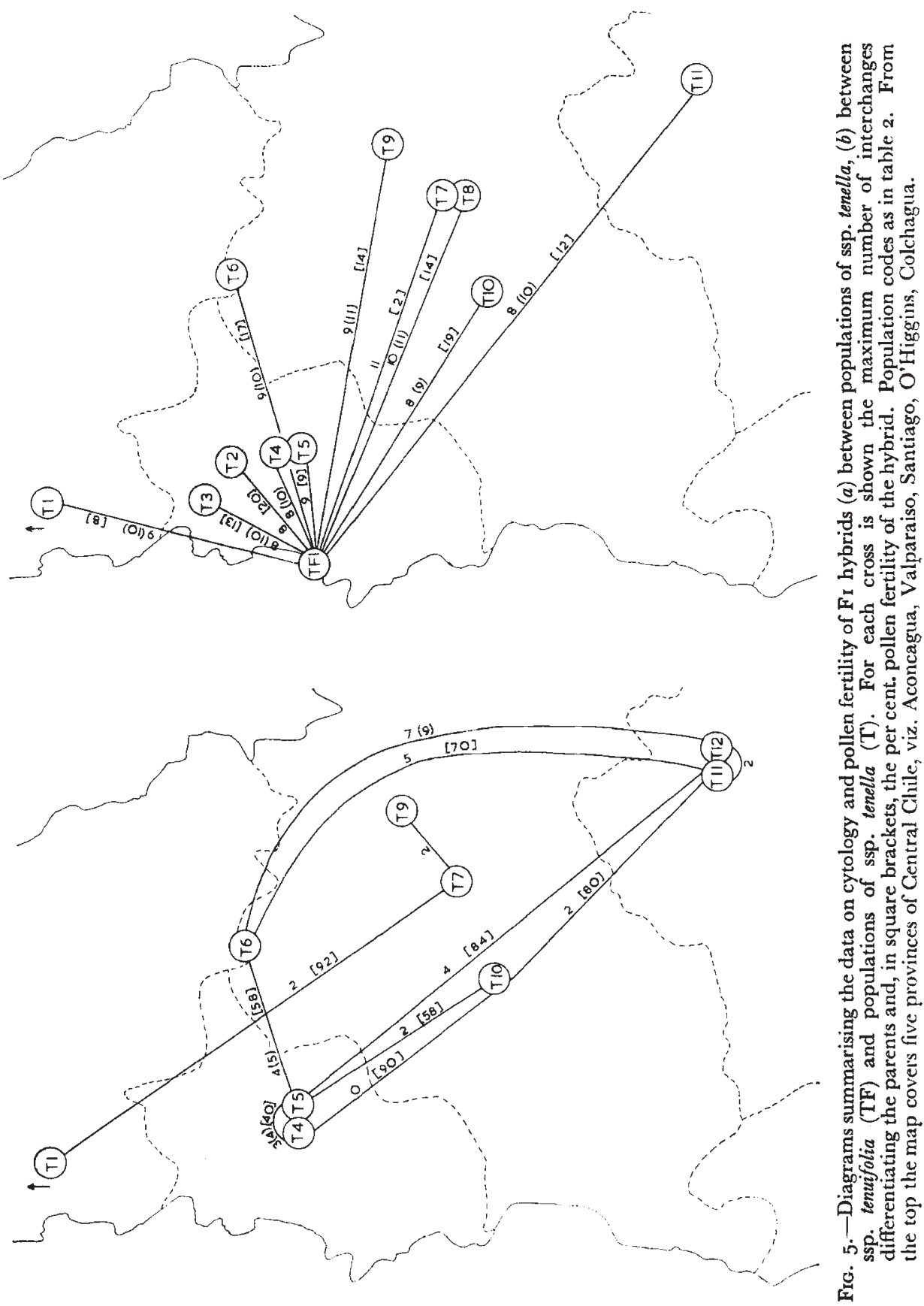

矛它它

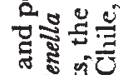
要

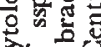

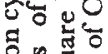

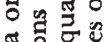
ปึ.

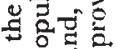
on 2 t? 然远 解。

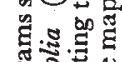

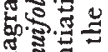
ด้ 的竞然气 哆 
It is exceedingly difficult to discern any pattern to the chromosomal rearranging that has occurred within ssp. tenella. Proximity of populations does not seem a constant factor, since $\mathrm{T}_{4}$ and $\mathrm{T}_{5}$, which occur on similar hillsides only io $\mathrm{km}$. apart in the Chilean Coast Ranges, differ by 3 or 4 interchanges, while $\mathrm{T}_{\mathrm{I}}$ and $\mathrm{T}_{7}$, which come from localities separated by $35^{\circ} \mathrm{km}$., differ by only two visible interchanges. Neither morphology nor altitude proved more useful than geography in forecasting the extent of cytological differences. On the basis of chromosomal similarity, two or three groups can be delimited within ssp. tenella, viz. (i) $\mathrm{T}_{1}, \mathrm{~T}_{7}, \mathrm{~T} 8, \mathrm{~T}_{9}$; (ii) $\mathrm{T}_{4}, \mathrm{~T}_{5}, \mathrm{~T}_{\mathrm{r}}, \mathrm{T}_{\mathrm{I}}, \mathrm{T}_{\mathrm{I} 2}$; (iii) T6. The sole member of group (iii), T6, does not belong to group (ii) but, in the absence of the necessary hybrids, we cannot determine whether or not it can be included in group (i). Populations within each group do not differ by more than two visible interchanges with at least one other population in the group, while they differ by four or more interchanges when crossed to members of another group. However, if the populations within a group share any common correlations, these cannot be determined. For example, group (ii) contains populations from the Chilean coast range and from the Andean foothills while group (i) contains populations from the Andes near Santiago and from the northern coast range in Coquimbo province. It is of interest to note (fig. $5^{b}$ ) that the populations in groups (i) and (iii) show a greater chromosomal divergence from ssp. tenuifolia $(9$, 1o or I I interchanges) than those included in group (ii) (8, in one instance 9 , interchanges).

The sterility of hybrids between populations of ssp. tenella varies as much as the amount of chromosomal divergence, and the two are generally correlated. Thus, the chromosomally most dissimilar populations, $\mathrm{T}_{9}$ and $\mathrm{T}_{\mathrm{o}}$, give a hybrid of very low pollen fertility (I I per cent.). However, an equally high pollen fertility ( $>80$ per cent.) is found in hybrids between populations differing by two $\left(T_{I 0} \times T_{I I}\right)$ or four $\left(T_{5} \times T_{I I}\right)$ interchanges, so it seems that the sterility of hybrids between populations of ssp. tenella, like that between the subspecies, may not depend entirely on chromosomal differentiation.

\section{DISCUSSION}

There can be little doubt concerning the essential unity of the South American clarkias. The morphological variation, although rather great, is of such a pattern that only partially intergrading, modal entities, the four subspecies, are recognised formally. The occurrence of a single chromosome number throughout the major part of the complex also accords with its unity. However, there has been a considerable amount of chromosomal differentiation within Clarkia tenella, usually accompanied by reduced hybrid fertility. The data show that, as in $C$. rhomboidea (Mosquin, I964), the low fertility of many interpopulational hybrids is not due entirely to visible chromosomal differentiation, so that cryptic rearrangements or genic factors 
must also be important. Indeed, the occurrence of anaphase bridges and/or fragments in some, mainly intersubspecific, hybrids strongly suggests that genotypically induced chromosome breakage may be important.

Clarkia tenella has its closest affinities with the North American C. davyi, a tetraploid $(2 n=34)$ species from coastal bluffs in central and northern California (Lewis and Lewis, 1955). Besides sharing the same chromosome number, these two species approach each other so closely in morphology that herbarium collections are sometimes difficult to identify. Despite this, however, Raven and Lewis (1959) have shown that $C$. davyi differs from a population of $C$. tenella ssp. tenella (population very close to our $T_{5}$ ) by at least 6 or 7 interchanges and that hybrids between them are of very low pollen fertility ( $c a .5$ per cent.). These authors have argued convincingly for the origin of C. davyi and $C$. tenella from a North American tetraploid ancestor, now extinct, whose genomes have contributed to at least three North American hexaploid species, in addition to the two tetraploids (Lewis and Lewis, I955).

The habitats described in this paper confirm that $C$. tenella resembles the other members of section Godetia in being adapted to relatively xeric and open plant communities comparable to those in California which were derived from the Madro-Tertiary Geoflora (Lewis, I953) and which have occupied an appreciable area only since the Miocene. As there is no evidence that ecological conditions suitable for migration across the tropics have been available since that period, Raven and Lewis (1959) concluded that the tetraploid ancestor of $C$. tenella crossed the tropics by some form of long-distance dispersal and we will proceed on this assumption.

In view of the essential unity of the Clarkia tenella complex it seems unlikely that more than one introduction has given rise to the South American populations. If this is the case, it is then necessary to determine which part of the variation within the species is closest to the ancestral condition. There is overwhelming evidence that in Clarkia (see e.g. Moore and Lewis, I $96_{5} a$ ), as in other groups of plants (Stebbins, I957), the self-pollinating species and populations have always arisen from cross-pollinating relatives. This leads us to conclude that the strongly allogamous $C$. tenella ssp. araucana is most like the original introduction into South America. Furthermore, since almost all populations of $C$. tenella as well as $C$. davyi, have $\mathrm{n}=17$, the 34 chromosome race of ssp. araucana is undoubtedly ancestral to the 32-chromosome race.

Clarkia tenella ssp. araucana is morphologically quite uniform and there has been no separation of recognisably different local populations; even those from the geographical extremes cannot be distinguished. However, the subspecies has become cytologically differentiated, most obviously into the two chromosome races. It is not known whether the $3^{2-c h r o m o s o m e ~ f o r m ~ h a s ~ r e s u l t e d ~ f r o m ~ t h e ~ c o m p l e t e ~ l o s s ~ o f ~ a ~}$ 
chromosome or from the loss of a centromeric region following reciprocal translocation, as has occurred in $C$. amena (Håkansson, I946). However, the latter is favoured because the extra chromosome of the I 7-genome is frequently included in $3^{-}, 5^{-}$or 7 -valent associations in hybrids with araucana-32. The distributional data suggest that the 32-chromosome race is perhaps better adapted to the more mesic conditions near the southern limit of the species. If true, this constitutes a unique example in Clarkia for which the evidence has hitherto consistently indicated that derived chromosomal races are adapted to more xeric habitats. It is interesting that Camissonia dentata has if bivalents throughout its range in North and South America except for a population at the southernmost limit in Arauco Province, Chile, which has 13 bivalents (Moore and Raven, unpublished, see Raven, I963). Each of the chromosome races in $C$. tenella ssp. araucana appears to be cytologically uniform with no internal barriers to gene exchange. However, the change in number is associated with chromosomal repatterning involving at least four or five interchanges and hybrids between 32 - and 34 -chromosome populations show about $5^{\circ}$ per cent. reduction of pollen fertility, but this differentiation is not nearly so great as that between most of the subspecies.

It is not known at what date the material from which the cultivar "Celestial" has been developed was introduced into Europe but morphologically and cytologically it is clearly within the range of variation found in natural populations of the 32 -chromosome race of ssp. araucana. Horticultural selection appears to have resulted solely in a more floriferous, compact inflorescence and in earlier flowering. (In I96I, with identical germination date and culture conditions, "Celestial" AR5 flowered on I $_{5}$ th June and the other araucana samples on i2th-i 7 th July.)

There is no doubt that ssp. ambigua is the selfing derivative having the greatest affinity with ssp. araucana. Both occupy very similar habitats, indeed they are often sympatric, while they are extremely close in habit, flower colour and general morphology. They differ in the smaller flowers and shorter hypanthium of ssp. ambigua and, most conspicuously, in their pollinating mechanisms. They also differ in flowering time; in the field and in cultivation, ssp. ambigua flowers two or three weeks earlier than the sympatric populations of ssp. araucana, showing a correlation between early flowering and autogamy that is common in the genus. This correlation, we believe, results from the advantage of autogamy in small remnant populations forced to inbreed following catastrophic selection for very early flowering (Moore and Lewis, 1965a). Hybrids between ssp. ambigua and ssp. araucana have a rather low pollen fertility (14-23 per cent.) although they show fewer chromosomal differences than any other intersubspecific combination. Interestingly, ssp. ambigua shows fewer differences with ssp. araucana-32 than with the 34 -chromosome race. This is surely the result of a parallel, rather than a common, 
evolutionary pathway in which some of the same chromosomes have been involved in interchanges in the course of independent derivation from ssp. araucana-34.

Neither ssp. tenuifolia nor ssp. tenella seems to bear any direct affinity with ssp. ambigua. The distinctive very short style of the latter is not approached at all in either of the others and this uniqueness, together with its close affinity with ssp. araucana, suggests that ssp. ambigua represents a single, and possibly relatively recent, essay into autogamy within $C$. tenella.

Subspecies tenuifolia is typically suited for cross-pollination, but its mature stigma is much closer to the anthers than is the case in ssp. araucana. Although generally smaller, its range of flower size overlaps substantially with that of ssp. araucana, but ssp. tenuifolia can be distinguished readily by its shorter hypanthium, and less robust, wellbranched habit, as well as by its quite separate geographical distribution. The data clearly suggest that ssp. tenuifolia has been derived from an araucana-like form by a process independent of that which gave rise to ssp. ambigua. The wide and discontinuous geographical separation of sspp. araucana and tenuifolia ( $350 \mathrm{~km}$., $3 \frac{1}{2}$ degrees latitude), together with their morphological divergence, suggests that the latter arose much earlier than ssp. ambigua. Interestingly, ssp. tenuifolia is largely restricted to the coast of northern Central Chile indicating that, in addition to the other characters noted, it may resemble ssp. araucana in an inability to occupy the more xeric habitats available to C. tenella. Subspecies tenuifolia and ssp. araucana show the highest degree of chromosomal divergence found within the species, and hybrids between them are of very low fertility (9 per cent. good pollen).

There can be little doubt that ssp. tenuifolia has given rise to ssp. tenella. They are often sympatric, have similar flowering periods, and intergrade in flower size and hypanthium length. In addition, certain late-flowering facies of some tenuifolia populations are indistinguishable from ssp. tenella in flower size and hypanthium length. The relatively small distance between the mature stigma and the anthers means that ssp. tenuifolia must in some instances be facultatively self-pollinating, particularly when the environmental component of style growth does not permit its full extension, and it is obvious that genetic changes of only modest scope are needed to transform some plants of tenuifolia into the obligately self-pollinating ssp. tenella. If the above sequence of events is correct, ssp. tenella would be the most derived part of the species, and this does seem to be the case. Lewis (1953) has shown that Clarkia evolution has involved a trend of increasing adaptation to more xeric communities, and it is as its ssp. tenella that $C$. tenella has invaded the dry inner coast ranges and Andean foothills of northern Central Chile and the arid northern portions of the Patagonian Province east of the Andes (Cabrera, I953). This is also the most variable subspecies, both morphologically and chromosomally, with a latitudinal range of at least ${ }_{13}$ degrees. The morphological variation falls into a pattern 
characteristic of autogamous groups. The amount of chromosomal differentiation within ssp. tenella varies considerably, from pairs of populations which show complete structural homology and high pollen fertility ( $>9 \circ$ per cent.) when crossed, to others which differ by at least 9 or Io interchanges and which form hybrids of extremely low pollen fertility (I I per cent.). Subspecies tenella is separated from all the other subspecies by considerable chromosomal repatterning, in no case are less than seven interchanges involved, accompanied by marked, usually severe, sterility barriers. The greatest chromosomal differentiation has taken place with regard to ssp. tenuifolia, which is often sympatric with ssp. tenella, but the most divergent populations of the latter

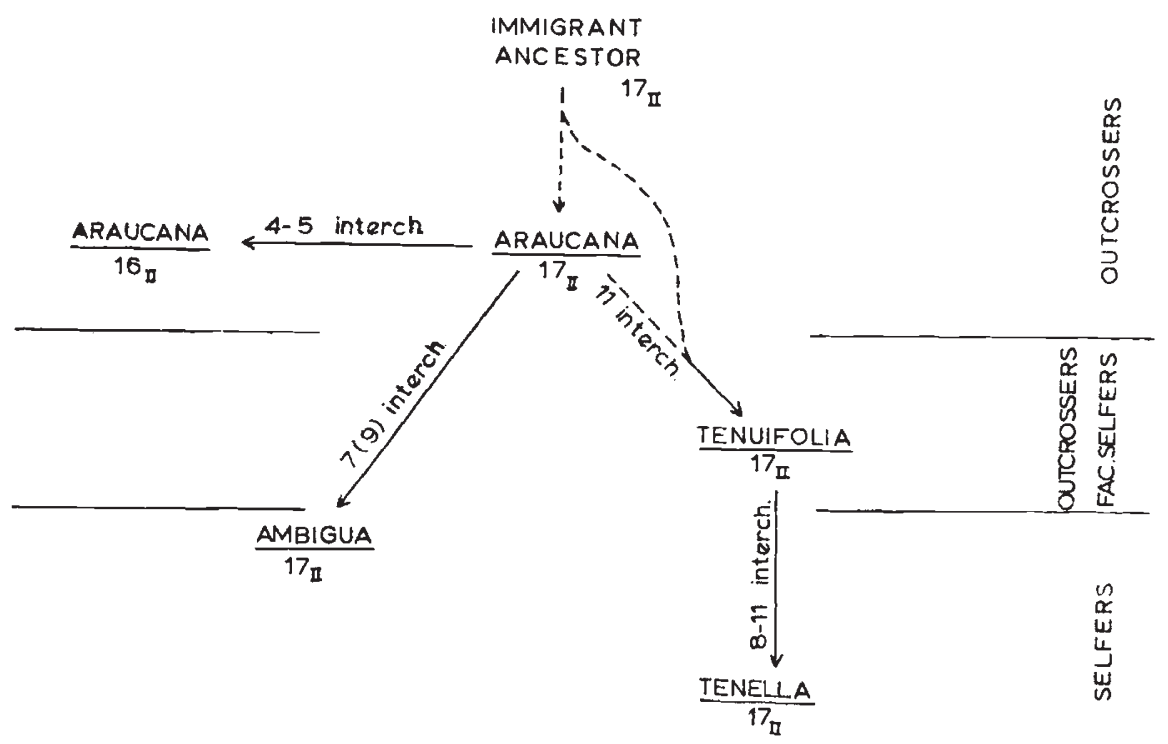

Fig. 6.-Diagram summarising the suggested course of evolution within C. tenella. The extent of chromosomal repatterning by means of interchanges is indicated, as are the chromosome numbers and breeding systems of the entities involved.

are neither the furthest from, nor the closest to, the population of ssp. tenuifolia used in the experimental studies.

The suggested course of evolution within Clarkia tenella, subsequent to its arrival in South America can be summarised as follows (fig. 6). The immigrant was a cross-pollinating, 34-chromosome form something like ssp. araucana. It was adapted to, and occupied, an area of moderate rainfall like that now found around Concepción, Chile, but it was probably restricted to rather open habitats. Subspecies tenuifolia arose from ssp. araucana or an araucana-like form and may have attained its present northern coastal distribution by migration along the more mesic aspects of the coast range. Alternatively, and we believe much more likely, the ancestral form may have been pushed north during the Pleistocene advance of the Valdivian Rainforest (Muñoz and Pisano, 1947) and, while ssp. araucana returned southwards with the 
subsequent increasing aridity, the derived ssp. tenuifolia was adapted to the changed environment in the manner of the more xeric derivatives of Clarkia in North America. With a further increase in aridity we can visualise the self-pollinating derivative ssp. tenella replacing ssp. tenuifolia everywhere except along the coast where it persists today in a more equable maritime environment. A comparable replacement, by a higher polyploid, restricted the older $C$. davyi to coastal habitats in California.

Subspecies ambigua probably arose from ssp. araucana relatively recently, presumably as a result of marginal isolation, in the area they now occupy jointly. This change to autogamy appears to have been fairly abrupt and may well have involved some rapid chromosomal reorganisation of the sort postulated for the origin of the autogamous Clarkia franciscana from the outcrossing $C$. rubicunda (Lewis and Raven, 1958). The transition from $C$. tenella ssp. araucana to ssp. tenella via ssp. tenuifolia is apparently much less abrupt than the foregoing. This may reflect the more gradual derivation of ssp. tenuifolia and ssp. tenella but, at least in the case of ssp. tenella, we think that a relatively rapid change was involved. The morphological and cytological diversity within ssp. tenella and, to a lesser extent, within ssp. ambigua is probably a consequence of their breeding systems but we cannot entirely discount the possibility that either of these subspecies comprises more than one change to autogamy.

The 32-chromosome race of $C$. tenella ssp. araucana arose as a result of chromosomal reorganisation during which it lost a centromere. The morphological identity and moderate cytological divergence of the two chromosome races suggests that this occurred relatively recently, perhaps as a result of inbreeding in small marginal populations following the southward migration of ssp. araucana.

An implication of this study is the large amount of potential variability carried by the propagule which crossed the tropics. Clarkia tenella has a considerable latitudinal spread (13 degrees), when compared with that ( 18 degrees) of the whole of the rest of the genus in North America, and it occurs in almost as wide a range of habitats. The morphological variation is rather great and the subspecies which can be recognised are separated by considerable chromosomal and genetic barriers to gene exchange. Fragmentation of the species, principally by means of chromosomal repatterning, has proceeded much more rapidly than the morphological divergence, an evolutionary situation which is not uncommon in the genus (Lewis, 1959, 1962; Snow, 1960$)$ and it is clear that the greatest amount of chromosomal differentiation has accompanied the change to self-pollination. The extent of the chromosomal diversification within $C$. tenella is greater than has yet been reported for any other species in the genus. This ability to exploit the opportunities presented by the migration to South America serves, in conclusion, to emphasise once again the evolutionary potential of segmental allopolyploid species of Clarkia. 


\section{Plate}

First metaphase in pollen mother cells of subspecies, intrasubspecific and intersubspecific FI hybrids of Clarkia tenella.

(a) ambigua, AI. I 7 II.

(b) araucana-32, $\mathrm{AR}_{4}$. I6 II.

(c) araucana-32, $\mathrm{AR}_{3} \times \mathrm{AR}_{4} . \mathrm{IV}^{\text {ch }}+\mathrm{I}_{4} \mathrm{II}$.

(d) araucana- $34 \times$ araucana-32, $\mathrm{AR}_{2} \times \mathrm{AR}_{3} .2 \mathrm{~V}^{c h}+\mathrm{III} \mathrm{I}^{c h}+\mathrm{I}$ o II.

(e) araucana-32 $\times$ ambigua, $\mathrm{AR}_{3} \times \mathrm{AI}_{\mathrm{I}} . \mathrm{XI}^{c h}+\mathrm{IV}^{c h}+9 \mathrm{II}+$ frag. 
$b^{5}=$
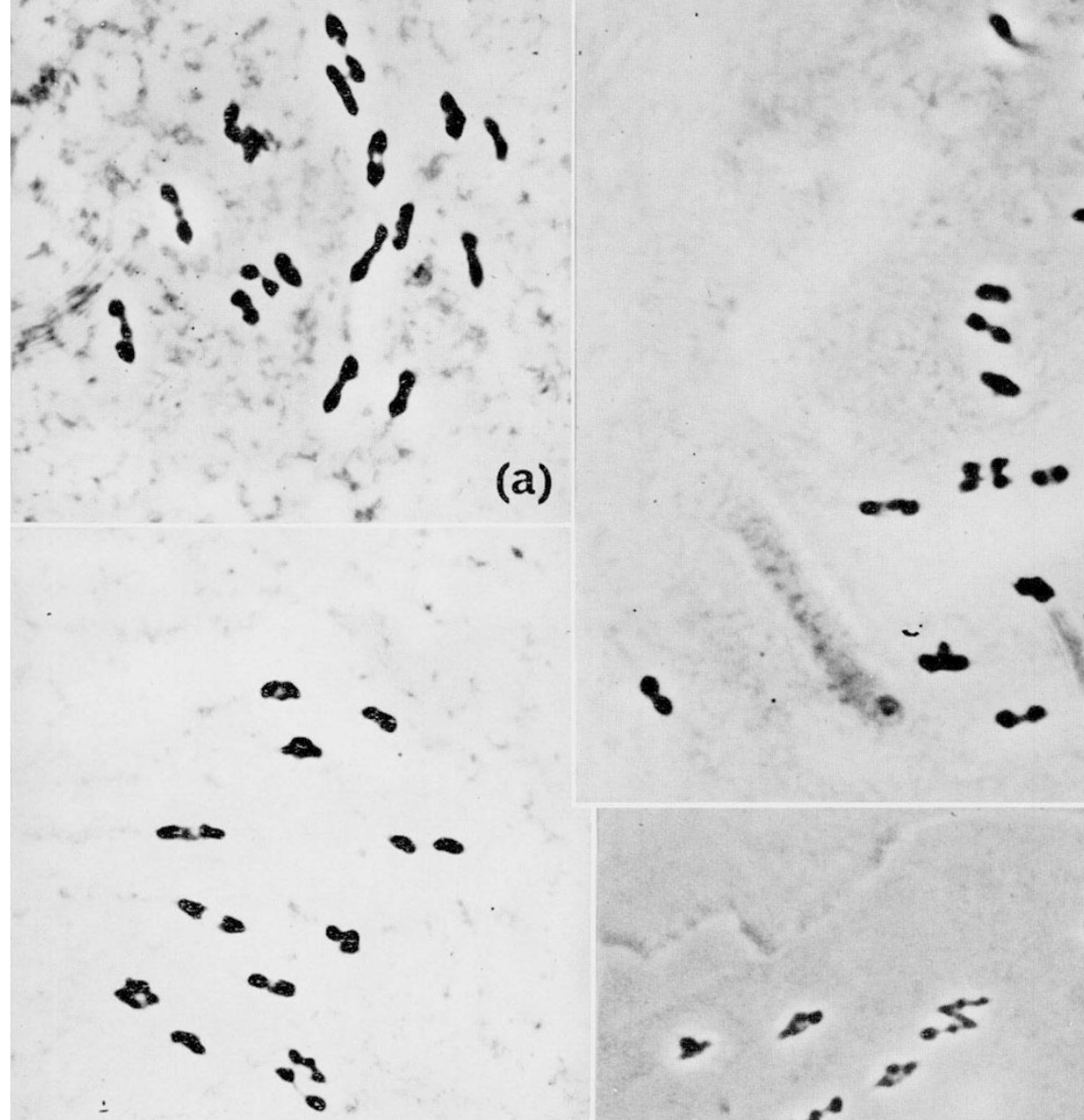

(b)

$-1$

4

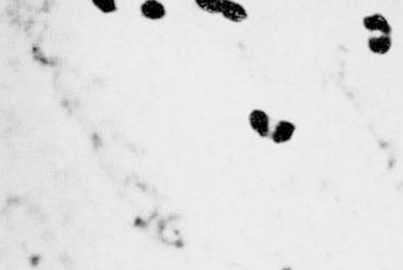

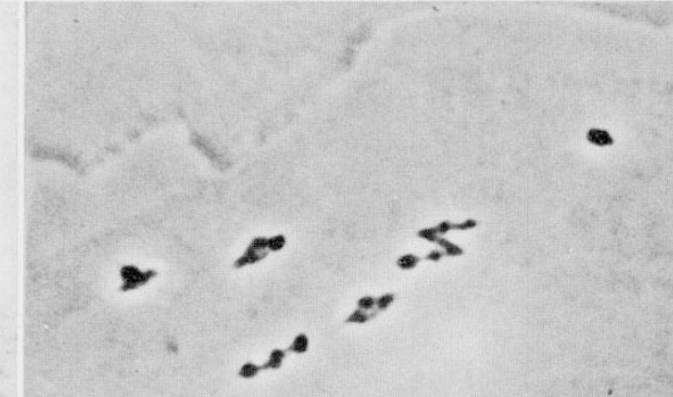

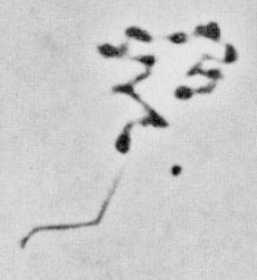

:

$$
\begin{array}{ll}
\text { (d) } & \text { (d) } 1 \text { Scale }=10 \mu
\end{array}
$$




\section{SUMMARY}

Clarkia tenella, comprising four subspecies, occurs throughout Central Chile and enters westernmost Argentina. Subspecies araucana, the most southerly, has large flowers and is cross-pollinated. Its northern populations are sympatric with the self-pollinated ssp. ambigua. The coastal ssp. tenuifolia, which is typically cross-pollinated, intergrades with the widely distributed, small-flowered, morphologically variable, self-pollinated ssp. tenella. The species has $2 n=34$, except for the southernmost populations of ssp. araucana which have $2 n=32$.

Hybrids between the subspecies are heterozygous for 4-I I or more interchanges and have greatly reduced pollen fertility. Additional differentiation is indicated by the irregular presence of bridges and, sometimes, fragments at meiotic anaphase.

The 34- and 32-chromosome races of ssp. araucana are cytologically uniform but hybrids between them are heterozygous for at least 4 interchanges. Populations of ssp. ambigua differ by 7 or more interchanges, while the range of chromosome differentiation in ssp. tenella varies from pairs of populations which are structurally homologous to others which differ by a minimum of 9 interchanges. No correlation can be detected between the extent of chromosomal divergence in ssp. tenella and the geographical, ecological or morphological attributes of the populations. Reduced pollen fertility of intra- and intersubspecific hybrids can largely, though not entirely, be correlated with the extent of interchange heterozygosity.

The data suggest that the 34-chromosome race of ssp. araucana most closely resembles the ancestral Clarkia in South America. In response to increasing aridity it gave rise to ssp. tenuifolia, which was later restricted to coastal areas by its derivative ssp. tenella as arid conditions increased further. Subspecies ambigua represents a separate and more recent change to autogamy from ssp. araucana. The $3^{2-}$ chromosome race of ssp. araucana has arisen quite recently and is the only known example in Clarkia of a derivative occupying more mesic conditions than its progenitor.

Acknowledgments.-This work was supported by a grant from the National Science Foundation to Harlan Lewis. We are indebted to the following friends for their valuable assistance to D.M.M. during his travels in Chile: Augustin Garaventa H., Limache; Carlos Jiles P., Ovalle; Ilse Koch, Valdivia; Clodomiro Marticorena R., Concepción; Carlos Muñoz P., Santiago; Gabriel Olalquiaja F., Santiago; Mario Ricardi S., Concepción; Federico Schlegel S., Santiago; Wilfried Stubbe, Valdivia.

\section{REFERENCES}

Cabrera, A. L. I953. Esquema fitogeográfica de la República Argentina. Rev. Mus. Eva Perón, 8, Secc. Bot., 87-1 68.

IARANSSON, A. I 946 . Meiosis in hybrid nullisomics and certain other forms of Godetia whitneyi. Hereditas, 32, 495-513.

HIORTH, G. 1941. Zur Genetik und Systematik der Gattung Godetia. Zeits. $f$. Vererbungsl., 79, 199-2 I9. 
LEWTS, H. 1953. Chromosome phylogeny and habitat preference of Clarkia. Evolution, 7, 102-109.

LEWIS, H. I959. The nature of plant species. Fourn. Ariz. Acad. Sci., r, 3-7.

LEWIs, H. 1962. Catastrophic selection as a factor in speciation. Evolution, 16 , $257-271$.

Lewis, H., AND Lewis, м. 1955. The genus Clarkia. Univ. Calif. Pub. Bot., 2o, 24 I-392.

IEWIS, H., AND RAVEN, P. H. I958. Rapid evolution in Clarkia. Evolution, I2, 319-336.

MOORE, D. M., AND LEWIS, H. I965a. The evolution of self-pollination in Clarkia xantiana. Evolution, 19, 104-1 14.

MOORE, D. M., AND LEWIS, H. 1965b. Las sub-especies de Clarkia tenella. Bol. Soc. Bot. Argentina, ro, 332-340.

moseurn, T. 1964. Chromosomal repatterning in Clarkia rhomboidea as evidence for post-Pleistocene changes in distribution. Evolution, $18,12-25$.

MUÑoz, C., AND PISANo, E. 1947. Estudio de la vegetación y flora de los parques nacionales de Fray-Jorge y Talinay. Agric. Técnica, 7, 71-190.

RAVEN, P. H. 1963. Amphitropical relationships in the floras of North and South America. Quart. Rev. Biol., 38, 15 I-177.

RAVEN, P. H., AND LEWIS, H. I 959. The relationships of Clarkias from two continents. Brittonia, II, 193-205.

sNow, R. 1960. Chromosomal differentiation in Clarkia dudleyana. Amer. Jour. Bot., 47, 302-309.

STEBBnN, G. L. 1957. Self-fertilisation and population variability in the higher plants. Amer. Nat., 9I, 337-354. 